\title{
AMSSM: leaders in primary care sports and exercise medicine
}

\author{
Karim M Khan
}

Obama, Lincoln, Elizabeth I, Merkel, Sarkozy, Streep/Thatcher, Papandreou, Berlusconi, Gadaffi, Henry VIII. Leadership is in the news and leadership influences outcomes. Primary care sports and exercise medicine has benefitted from transformational leadership in certain countries. Building a national primary care sports and exercise medicine body with 1500 or more members requires a guiding coalition ${ }^{1}$ to focus on the common, compelling goal. ${ }^{2}$ It takes a community and it takes a professional lifetime. If quasi-leaders cannot subvert their personal ambition to genuinely support each other to benefit, the collective things go awry. ${ }^{3}$ Underperformance has many faces.

The American Medical Society for Sports Medicine (AMSSM) has benefitted from 21 years of transformational leadership. The result is a brilliantly supportive milieu for American primary care physicians and fellows which means better outcomes for patients. Lives saved. AMSSM is a jewel in the global primary care sports and exercise medicine crown. In a free, very competitive, market, US primary care physicians vote with their feet for AMSSM. Membership is accelerating, conference attendance climbs year over year and balance sheets point to sustainability. The organisation may serve as a role model, a 'success story' for some, and as a result AMSSM is now able to offer terrific value for international physicians who wish to join. More on that over the page.

\section{Five ways that AMSSM adds value - for physicians and patients}

1. Facebook effect - 845 million people cannot be wrong. People join Facebook to share common interests - it provides a forum. That 2000+ year old Roman word, forum, highlights the need to gather. No woman or man is an island. AMSSM is the nationwide sports and exercise medicine interest group exclusively dedicated to US primary care sports physicians. No need to get primary care on the agenda.

Correspondence to Karim M Khan, The University of British Columbia, Department of Family

Practice, Professor, UBC, Centre for Hip Health and Mobility, Vancouver, British Columbia V6T 1Z3, Canada; karim.khan@ubc.ca
Primary care sports and exercise medicine is the agenda. No need for primary care board members or to negotiate for annual meeting programming. This liberates the leaders from advocating internally - they can focus on providing value for members. What does that look like?

2. Education - the bedrock of professional organisations. Dr James Andrews emphasised education (and research) among his eight tips for success in sports medicine. 'If you are involved in research and education, it will make you and others better.' Who taught you how to do the thing you love the most - play basketball, be part of a rock band, hike in striking natural beauty? You probably did not learn it by yourself. Peer-teaching is a gift, we acknowledge the influence of our predecessors in sports and exercise medicine.

AMSSM provides education in at least five major categories. These include; (i) members teaching fellows across the USA, (ii) the annual meeting programme and the rich workshops available there, (iii) AMSSM's primary care education materials including case reports on the website/branded textbook, (iv) the suite of clinical guidelines (eg, for concussion) and (v) curriculum (eg, ultrasound training) for sports and exercise medicine.

The 2012 Annual Meeting sees the launch of the very exciting ECG interpretation training programme, a web-based, worldwide partnership between AMSSM, major cardiology bodies and FIFA, hosted on the BMJ Learning platform (www. learning.bmj.com). Another practical illustration of AMSSM's increasing global influence and focused commitment to primary care sports and exercise medicine issues.

3. Research-adding to the evidence base, is fundamental to defining our discipline. The AMSSM provides leadership through coordination (to avoid duplication, harness synergies), education (how to do it) and increasingly, financial seed funding (via the AMSSM Foundation). The AMSSM has provided great value to members by negotiating major discounts for access to BJSM (16 issues annually) the Clinical Journal of Sport Medicine (6 issues annually) and Sports Health: A Multidisciplinary Approach (6 issues annually).
4. Practice tips and career advice - being a successful physician requires more than 'content knowledge', and AMSSM provides a community that mentors young physicians formally and informally. A conversation at the bar on the eve of the 2010 Annual Meeting in Cancun provided one fellow with a critical connection that led to her becoming aware of a college job opportunity she later landed. These interactions are ubiquitous at the annual meetings and deliberately fostered by AMMSM leadership policies. From the outside, the formula looks like (1) invest in creating a great conference programme; (2) encourage folks to stay at the one hotel and include social events within a very reasonable registration fee; (3) schedule formal networking events (eg, Fellowship Forum, Team Physician Breakouts, Special Interest Breakouts) and (4) leave "unscheduled time' for the magic to happen.

5. Advocacy - the 'union' role. I appreciate the important distinction between the physicians 'guild' (AMSSM in this case) and the licensing bodies (state-based in the USA). And without getting into the merits/demerits of labour unions, Steinbeck's Grapes of Wrath and Mitt Romney's 'we should have let Detroit go bankrupt', the AMSSM supports primary care sports and exercise medicine physicians in grappling with the 'business' side of medicine. You'll find an annual meeting workshop with experts sharing the pros and cons of various settings in which to practice sports and exercise medicine, advice on billing, marketing and the RVU system.

\section{Why you will love Atlanta in April}

'Game On!' The Annual Meeting in Atlanta (April 21-25) is the celebration, the Carnivale, the doctorpalooza, that vivifies all I described above. You'll learn to implement the Injury Prevention evidence, be edified about ECG interpretation, pumped to prevent sudden death, and revel in the review of Biologics. I'm looking forward to updates on Care of the Elite Athlete, no longer labouring with Hip and Groin Pain, understanding The Endurance Athlete, and hearing Pulitzer Prize winner George Dohrmann's scoop on Paediatric Athlete Controversies. And that's just a start (http://www.amssm.org/ Content/pdf\%20files/2012AMBrochure. pdf). I counted 13 Instructional Course Lectures (ICLs) over and above the core programme. All relevant to primary care sports medicine. Lucky 13 keynote lecturers complemented by 99 expert faculty all readily available and keen to chinwag with you at the Atlanta Hyatt Regency. 
Fellows and mentors should attend the dedicated Fellowship Forum (chaired by Mark Stovak) and the Fellowship Fair. Last year over 150 fellows commented on the supportive culture of AMSSM's annual meeting and the ease of access to faculty from the USA and overseas.

\section{International sports and exercise clinicians win too!}

If AMSSM sounds attractive, you are a certified $\mathrm{MD}$ or $\mathrm{DO}$ clearly committed to sports and exercise medicine but you live outside the 50 States, do not worry! In fact (whispering this part....shhh!) you can actually join for less than US members pay! Do not tell your US colleagues or they will insist you buy the beer at the annual meeting. Seriously, in a laudable initiative to reach out, AMSSM have a very generous international membership deal. Check out the website http://www.amssm.org/ Membership.html. Benefits include access to three journals: BJSM (16 issues), Clinical Journal of Sport Medicine (6 issues) and Sports Health: A Multidisciplinary Approach (6 issues). You'll also be able to access the members-only area of the AMSSM website which includes the option to join the AMSSMNet Listserv and Forums. And of course, you get conference discount too!
Sign up on the website today and book your flight to Atlanta!

\section{This issue of BJSM}

Highlighting BJSM's clinical focus we highlight the challenges associated with sickle cell trait (see pages 325 and 312), the interpretation of ECGs (see page 335), the contribution of echocardiography (see page 341), concussion assessment (see page 365 ) as well as an analysis of physical activity behaviour of clinicians, fellows and medical students (see page 360 ). The complex question, 'Does exercise make you eat more in response?' is reviewed by the global leaders on the topic (see page 315). We will expand on the BJSM blog (http://blogs.bmj.com/bjsm/) and via BJSM's popular podcasts (http://podcasts. bmj.com/bjsm/). Together these digital education resources reach over 40000 eyeballs monthly. If you follow @BJSM_ $\mathrm{BMJ}$ or BJSM on Facebook you can readily screen for updates, filter what's best for you. BJSM's Twitter community is over 3000 strong, and we were ranked by Webinicia as a world leader in social media. An appropriate partner for AMSSM (and our seven other member societies who will be highlighted in upcoming issues of $B J S M)$ ! Congratulations to AMSSM on 21 great years at the heart of US primary care sports and exercise medicine. And let me know how BJSM can serve you whether you are in Atlanta or Zambia (karim. khan@ubc.ca).

PS: BJSM is very keen to work with all member societies who aim to promote sports and exercise medicine. The challenge for sports medicine organisations is to collectively grow in influence, and to wipe out the scourge of physical inactivity and injury. We are not competing among societies for a fixed group of members. The AMSSM has a series of 'exchange lectures' at the annual meeting, underscoring the importance of collaboration among societies.

\section{Competing interests None.}

Provenance and peer review Commissioned; internally peer reviewed.

Received 22 February 2012

Accepted 22 February 2012

Br J Sports Med 2012;46:301-302.

doi:10.1136/bjsports-2012-091099

\section{REFERENCES}

1. Kotter J. Leading change: why transformation efforts fail. Harvard Business Reviews 2007:96-103.

2. Hackmann R. Leading teams: Setting the stage for great performances: Harvard Business School Press, 2002.

3. Lencioni P. The five dysfunctions of a team. New York: Jossey Bass - Wiley, 2002. 